\title{
THE REALITY OF DIGITAL CURRENCY AS A FINANCIAL MEDIUM OF EXCHANGE
}

\author{
Ralph E. McKinney, Jr. Aston University, Birmingham, UK \\ Lawrence P. Shao, Marshall University, Huntington, WV, USA \\ Dale H. Shao, Marshall University, WV, USA \\ Duane C. Rosenlieb, Jr., Esquire, WV, USA
}

\author{
dx.doi.org/10.18374/JIFS-13-3.5
}

\begin{abstract}
This paper presents a discussion of the requirements for the long term acceptance of digital currency as a financial medium of exchange through the examination of fundamental criteria associated with common tender and the examination of selected digital currencies. According to the U.S. Treasury, digital currencies are subject to regulation if that digital currency has a substitutive purpose for facilitating exchanging goods and services (Financial Crimes Enforcement Network, 2013). Although governments can place stipulations on currencies, users of common tender, such as digital currencies, expect at least three basic privileges for a digital currency to evolve from conception to realization. First, a digital currency must be considered intangible personal property similar to trademarks, copyrights, and patents. Second, ownership disputes must be subject to a system such as a Judicial Proceeding or Binding Arbitration to resolve property conflicts. Finally, a digital currency must be subject to similar regulation as other financial instruments (e.g., legal tender, scrip, and credit cards) used in facilitating exchanges.
\end{abstract}

Keywords: Digital currency, common tender, currency regulation, virtual currency, medium of exchange. 